\title{
JORRO DE EFEITOS: LAÇOS SANGUÍNEOS ENTRE TRASH E GRAND GUIGNOL
}

\author{
Henrique Saidel ${ }^{1}$
}

\section{Resumo}

Trash quer dizer lixo, e tudo o que se pode relacionar com a noção de lixo. Lixo cultural, artístico, técnico e intelectual - em seus mais variados sentidos. Com especial atenção à crítica cinematográfica, o artigo transita pelo universo conceitual do trash, apontando práticas irônicas aí implícitas. O Grand Guignol (do início do século $\mathrm{XX}$ aos dias atuais) surge, então, como exemplo privilegiado do trash no teatro.

Palavras-chave: trash, ironia, Grand Guignol.

\begin{abstract}
Trash means rubbish, and anything that may relate to the concept of rubbish. Cultural garbage, artistic, technical and intellectual - in its most varied ways. With special attention to film criticism, the article carried by the conceptual universe of trash, pointing ironic practices that are implicit. The Grand Guignol (from the beginning of twentieth century to present day) appears then as prime example of trash in the theatre.
\end{abstract}

Keywords: trash, irony, Grand Guignol.

\section{Conceitos difusos}

Frequentemente marcando a obra de diversos artistas cênicos, como Gerald Thomas e Vigor Mortis ${ }^{2}$, a idéia de trashé tão evidente quanto nebulosa. Nebulosidade advinda da acentuada abrangência que essa denominação ganhou nas últimas décadas, aliada à quase inexistência de bibliografias específicas destinadas ao assunto. Se a palavra trash pulula no imaginário popular contemporâneo (urbano, sobretudo), ela tem sérias dificuldades em encontrar respaldo teórico que a auxilie na sua instituição como instrumento e parâmetro de análise. No entanto, é possível deparar-se com seu universo conceitual em veículos de comunicação pouco ortodoxos, como sites, blogs, jornais, revistas especializadas, zines, etc.

\footnotetext{
${ }^{1}$ Mestre em Teatro pelo PPGT-UDESC sob orientação do Prof. Dr. Edelcio Mostaço. Diretor, ator, cenógrafo e pesquisador, com formação em Direção Teatral pela Faculdade de Artes do Paraná. Integrante-fundador da Companhia Silenciosa (Curitiba, Paraná).

2É possível ainda citar outras companhias curitibanas atuais que transitam por este universo, como Barridos da Cena, Elenco de Ouro, Companhia Silenciosa e Heliogábalus.
} 


\section{Urdimento}

${ }^{3}$ Naïf em francês significa ingênuo, ligando-se à idéia de arte popular, "primitiva".
Grosso modo, trash (traduzido do inglês) quer dizer lixo, e tudo o que se pode relacionar com a noção de lixo. Lixo cultural, artístico, técnico e intelectual. É na crítica cinematográfica que surge o termo trash, para designar determinados tipos de filmes, frequentemente de baixo orçamento e salpicados de proeminentes defeitos técnicos.

Kleber Mendonça Filho (2005), crítico de cinema, questiona, de início, o estatuto do lixo nos dias atuais: se até pouco tempo atrás o lixo era o fim do ciclo vital de um produto, refugo descartado e abandonado, hoje o lixo é constantemente reciclado, fonte renovável de matéria prima, sinônimo de dinamicidade produtiva. O lixo proporciona releituras, perdendo seu caráter desprezível, inútil - tanto em termos materiais e econômicos, quanto em termos sociais e artísticos.

O autor apresenta a definição "conservadora" de trash que o entende como uma obra de arte nä̈f , fruto da produção de um artista inapto, limitado na técnica e na articulação de idéias. O artista não tem a intenção de apresentar algo mal feito, ele cria o lixo distraidamente, sem perceber o fato - visível a uma abordagem externa. $\mathrm{O}$ criador (que, obviamente, não intitula a si mesmo como trash) julga ter realizado seu intento, ignorante da própria precariedade. $\mathrm{O}$ trash, nesse sentido, é um julgamento exógeno, aparecendo muito mais como percepção distanciada de um malogro artístico que como estratégia coerente de linguagem. $\mathrm{O}$ olhar do espectador - ao comparar qualitativamente a obra a outras que considera similares - flagra os defeitos da obra e rotula-a como lixo. Esse olhar, no entanto, nem sempre é depreciativo: é, também, um olhar de admiração e mesmo de carinho pela ingenuidade. $\mathrm{O}$ fenômeno trash é lido, assim, como um evento de ironia observável - ou seja, quando, a partir de determinadas situações, "o observador irônico reconhece ou descobre que este algo pode ser olhado como na verdade o inverso, em algum sentido, daquilo que pareceu ser à primeira vista ou a olhos menos aguçados ou a mentes menos informadas” (MUECKE, 1995, p. 61).

Os filmes do diretor norte-americano Ed Wood, como Plano 9 do espaço sideral, de 1959 (famoso como o pior filme do "pior diretor de todos os tempos”), e do brasileiro José Mojica Marins (o Zé do Caixão), são exemplos desse trash não-intencional, nä̈f.

Em acréscimo a essa primeira visão do trash, destaca-se a existência de artistas que, aproveitando o caráter reciclável do lixo, se utilizam das características do trash (a rusticidade, o precário, o mau gosto, o "mal feito", o defeituoso, o grotesco, o gosto pelo bizarro, o excesso de efeitos, a falta de recursos financeiros) para construírem obras que criticam e subvertem justamente as fórmulas e os padrões considerados como "de qualidade" e "bom gosto”, que ocupam hegemonicamente o mercado da arte. 
Usando a obra do cineasta John Waters (diretor de Pink Flamingos, 1972) como exemplo, o crítico percebe como pode ser invertida a lógica ingênua do trash, em favor de uma poética intertextual, irônica (HUTCHEON, 2000), que se utiliza de elementos "errados", "malsucedidos" para contestar e alargar as fronteiras do belo, do aceitável, ao mesmo tempo em que estabelece com o público um forte vínculo efetivo/intelectual baseado subliminarmente na atração exercida pelo trash naïf. Trash como elemento de ironia instrumental: quando "o ironista, em seu papel de ingênuo, propõe um texto, mas de tal maneira ou em tal contexto que estimulará o leitor a rejeitar o seu significado literal expresso, em favor de um significado 'transliteral' não-expresso de significação” (MUECKE, 1995, p. 58). Assim, o trash de Wood é oposto ao de Waters, sendo que a intencionalidade é um dos principais fatores de distinção.

Ecoando o lema punk "faça-você-mesmo", muitos artistas defendem uma arte onde se valoriza a precariedade, a despreocupação com o "bom acabamento”, a impulsividade, a improvisação, a não necessidade de grandes orçamentos, como sinônimos de uma atitude mais "pura" por parte do artista, que não se submete aos ditames do "política e esteticamente correto". Petter Baiestorf e Cesar Souza, cineastas independentes da cidade de Palmitos, em Santa Catarina-dois dos maiores e mais prolíficos produtores atuais de cinema trash no Brasil - explicitam, não sem uma boa dose de sarcasmo, algumas de suas preferências no Manifesto canibal (2002):

Um Kanibaru Sinema antropofágico, primitivo, selvagem, niilista, ateu e caótico, mas de uma pureza maldita capaz de assustar tento os colonizados quanto os colonizadores. [...] A opção de filmar com equipamento $V H S-C / S-V H S / D i g i t a l / S-8$ filmes amadores de qualquer estilo e qualquer duração. [...] A opção de usar atores amadores elou amigos pessoais que se coloquem, de livre arbítrio, a disposição. A opção de se utilizar do Kanibaru Sinema e sua estética do caos para finalmente poder flertar com a estética da falta de estética. Leia-se aqui: a opção por destruir todos os valores estéticos (BAIESTORF; SOUZA, 2002).

Mais àfrente, os artistas detalham suas estratégias, revelandoprocedimentos bastante recorrentes e característicos de uma obra com vocação trash:

FIGURINOS: Pegue-os nas campanhas de arrecadação de roupas para pobres (de preferência nas campanhas de inverno, quando as roupas são melhores). Peça roupas velhas aos parentes $e$ amigos. Roube uniformes militares nos quartéis (os recrutas costumam negociar apetrechos militares por um precinho bem camarada). Faça seus figurinos exclusivos utilizando-se de lixo, como plásticos, latas, 
restos de tecidos, cascas de árvores, etc. Se for o caso, coloque seus atores interpretando pelados. [...]

PESSOAL/ELENCO: Utilize seus amigos e freaks em geral. Punks, putas, aleijados reais e mendigos são uma ótima opção, mas guarde uma parte de seu orçamento para pagar a eles um cachê, mesmo que simbólico. [...]

EQUIPE-TÉCNICA: Faça você mesmo tudo, assim o filme sai do jeito que você quer. [...]

EQUIPAMENTOS: Utilize qualquer tipo de câmera. Se você não tiver uma, arranje emprestado ou, ainda, você pode roubar uma. [...] Sua mensagem é o que importa, qualidade é coisa de cara reprimido!!! (BAIESTORF; SOUZA, 2002).

\section{Do cinema às outras artes}

Se a origem do termo trash encontra-se na história do cinema, é interessante acompanhar o seu desenvolvimento dentro dessa linguagem (o paralelismo existente entre cinema e teatro, enquanto manifestações cênicas distintas, é, no entanto, evidente). Com freqüência, críticos e cinéfilos estabelecem uma categorização: a) os filmes $B$ - produções ligadas à indústria cinematográfica, realizadas por estúdios oficiais e que contam com um orçamento visivelmente menor que os chamados filmes A, além de trabalharem com temas controversos; b) os filmes trash - produções independentes ou não que apresentam as mesmas características do trash naïf, não-intencional; c) os filmes underground ou marginais - obras independentes (rejeitando o círculo comercial mantido pela indústria do entretenimento), de forte cunho provocativo e subversivo, caracterizado pelo experimentalismo e pela pesquisa de linguagem, muitas vezes utilizando parodicamente os recursos estilísticos do trash.

Essa diferenciação mostra-se um tanto frágil ao ignorar que o trash (intencional e não-intencional) manifesta-se, em última instância, tanto em produções de estúdios tradicionais quanto em produções independentes. O trash, de fato, se coloca como fator estético (de processo, de resultado) e não como categoria baseada na existência ou não de um aparato técnico ou mercadológico específico exterior ao ato criativo. No entanto, tal categorização reforça um ponto-chave: o diminuto montante financeiro disponível para a realização da obra - o orçamento é sempre insuficiente para se realizar integral e convencionalmente as ambições do artista, que insiste em colocálas em prática mesmo assim. 
Segundo A. C. Gomes de Mattos (2003), a denominação B (de 1930 a meados de 1960) refere-se a filmes de baixo custo, filmados em no máximo três semanas, destinados a preencher a programação das salas de cinema. Em uma mesma seção, o espectador assistia um filme A e um B, ou dois B acompanhados de um curta-metragem. O reaproveitamento mais ou menos disfarçado de imagens e locações de filmes anteriores era prática corrente nos filmes B.

Um aspecto do cinema B que é decisivo para a consolidação do trash é o chamado cinema de exploração ou exploitation. Para Lúcio dos Reis Piedade (2002), o termo exploitation define filmes que têm como principal objetivo tirar proveito a partir da exploração sistemática de temas ou formas considerados polêmicos ou tabus. Segundo Piedade, o estudo do cinema de exploração pode ser estruturado em quatro vertentes: a) cinema de exploração clássico: produzidos com pouco dinheiro, entre 1920 e 1959, abordando temas "proibidos" ou de "mau gosto”, como sexo, nudez, prostituição, drogas e outros vícios, utilizando sets mal-feitos, imagens de arquivo, apresentando erros de continuidade e recursos simplórios de câmera, montagem e som; b) exploitation do pós-guerra: ênfase em documentários médicos sobre higiene física e mental; c) explosão do exploitation a partir de 1959 com o surgimento de sub-gêneros, como o sexploitation (sex + exploitation), blaxploitation (black + exploitation); d) generalização em várias partes do mundo, predominando as influências do cinema mainstream norteamericano e, em especial, do horror inglês.

O sexploitation teve início da década de 1940, com a produção de filmes burlescos (garotas exibindo o corpo em shows musicais) destinados aos soldados norte-americanos no front de batalha, além dos goona-goonas (nudez de índios americanos, africanos, balineses em locações exóticas) e dos filmes nudistas. Em 1950 surgiram os nudie-cuties, caracterizados pela exibição parcial da nudez feminina - seios, nádegas, pêlos pubianos - sem sugestão de atos sexuais, apoiada em uma narrativa simples e bem-humorada; cruzamento malicioso entre os filmes burlescos e nudistas. Mas é entre 1965 e 1972 que a relação entre sexo, violência e horror vai florescer com força e lançar as bases do trash atual, com o surgimento de três vertentes do sexploitation: a) roughies - filmes violentos, com estupros, torturas e outras brutalidades, onde mulheres são maltratadas por homens e outras mulheres em fúrias passionais; b) kinkies - onde o fetichismo é o principal fio condutor, com inúmeras cenas de sadomasoquismo, bondage, espancamentos, dominações e toda sorte de "perversões" e mortes sangrentas; c) ghoulies - caracterizados pelos "elementos macabros ou sobrenaturais, a utilização de clichês de filmes de suspense e terror, além do sangue e morte recorrentes, com detalhamentos de eviscerações e desmembramentos" (PIEDADE, 2002, p. 117). Se os roughies, kinkies e ghoulies não chegam aos extremos explícitos do hardcore (1970 em diante), com certeza 


\section{Urdimento}

forjaram de maneira contundente uma das práticas temáticas trash de maior repercussão: a "bizarra" e instigante fusão entre sexo, violência, sangue, morte e horror.

Os mais influentes filmes de horror da história do cinema foram produzidos de forma independente, marginal (PIEDADE, 2002). Marcado desde 1896 até a década de 1940 pelo expressionismo alemão e seu clima fantástico, e pela explosão da ficção científica dos anos 50, o horror cinematográfico encontra seu amadurecimento em 1960, com o renascimento do horror gótico (castelos medievais cheios de corredores úmidos e escuros, vilões monstruosos e perversos, jovens vítimas inocentes, lendas e maldições tenebrosas...) e o aumento da violência e do erotismo.

Eéna exploração do asco, do profundamente repelente expresso por essa vulgaridade explícita que esse filme de horror-exploitation vai erigir as suas estruturas, rompendo as barreiras e, através da banalização do sangue e das tripas expostas, redimensionando os cânones do que é permitido mostrar nas grandes produções. Essa exposição excessiva do imaginável (no lugar do inimaginável dos tradicionais filmes de monstros) - já que muitas das situações mostradas são uma exacerbação de uma realidade familiar - talvez seja a chave para a ambigüidade de relações do espectador para com esses filmes (PIEDADE, 2002, p. 23).

Em relação à forma narrativa básica dos filmes de horror, Piedade salienta:

Não é preciso muito esforço para ver as bases conservadoras sobre as quais desenvolveu-se o gênero, principalmente até os anos 70. A fórmula, aplicada à exaustão, sempre foi a inserção de um elemento perturbador - uma bolha vinda do espaço ou um lobisomem, se quisermos - à ordem estabelecida. Essa ameaça vai desestruturar esse equilíbrio e o grande momento desses filmes é a volta à normalidade, aqui expressa como o status quo (2002, p. 24).

Ao longo das décadas de 1960 até 1980, companhias como a inglesa Hammer e a AIP, e diretores como Roger Corman, Herschell Gordon Lewis (Banquete de sádicos, 1963), José Mojica Marins (Esta noite encarnarei no teu cadáver, 1966), George Romero (A noite dos mortos vivos, 1968), Roman Polanski (O bebê de Rosemary, 1968), William Petter Blatty (O exorcista, 1973), Tobe Hooper (O massacre da serra elétrica, 1973), John Carpenter (Fog - a bruma assassina, 1980), Ivan Cardoso (O segredo da múmia, 1981), Ridley Scott (Blade Ranner, 1982), Sam Raimi (Uma noite alucinante, 1983), Wes Craven (A hora do 


\section{Urdimento}

pesadelo, 1984), entre inúmeros outros, contribuíram para a consolidação de novos cânones que iram transformar os filmes B (e underground) de horror em sinônimos de arte trash.

Uma extensa galeria de personagens-tipo é criada e constantemente revisitada: vampiros, múmias, lobisomens, fantasmas, demônios e todo tipo de seres sobrenaturais, com particular preferência por zumbis (mortosvivos); extra-terrestres, máquinas e robôs inteligentes, animais descomunais e monstros em geral; serial killers, psicopatas, maníacos, tarados, pervertidos, sádicos e masoquistas. Práticas "proibidas" como ataques de fúria, ações violentas, assassinato, tortura, incesto, canibalismo, necrofilia, satanismo e libertinagem também são freqüentes.

O cinema gore ou splatter ${ }^{4}$, que, numa inspirada tradução para o português transformou-se em sangue-e-tripas, promove uma verdadeira carnificina na tela, com constantes eviscerações e esquartejamentos. Mattos fornece uma das chaves para a compreensão desse tipo de filme que carrega a "essência" do trash:

O filme gore procura provocar nos espectadores uma reação violenta de desgosto, mostrando os simulacros de corpos retalhados de seres humanos ou de animais banhados em sucedâneos de hemoglobina. Tudo é encenação, ao contrário da representação documentária do sofrimento e da morte, tal como a encontramos, por exemplo, nos jornais cinematográficos de guerra. É um tipo de filme que permite truques espetaculares por um preço muito baixo: bastam espessas camadas de maquilagem, carniças e vísceras de animais, e uma boa provisão de líquido espesso simulando sangue (2003, p. 62)

É importante vislumbrar o caráter espetacular, de teatralidade que impregna essas produções. O trash está intimamente ligado à idéia de encenação, de falso, fake. Por mais assustador e nojento que seja, o sangue trash é sempre sangue artificial ${ }^{5}$, o sofrimento e a morte trash são sempre sofrimento e morte fingidos. E o fundamental: a artificialidade e o fingimento apresentam-se em grau tão superlativo que é impossível não percebê-los como tais. A materialidade, a natureza mesma das coisas é exposta e fruída dentro da obra, encarada como elemento poético, exibindo claros traços de metalinguagem. A realização (ou a tentativa de realização) de "efeitos especiais" surpreendentes, inenarráveis, assustadores, emocionantes, também é marca do trash: o efeito que mais parece um "defeito", e que é mantido na obra, sem maiores pudores afinal, o conceito de "qualidade" do trash não é, evidentemente, o mesmo conceito pretendido por outros tipos de obras de arte. O efeito trash realiza-se, de certa maneira, na sua não realização.

${ }^{4}$ Gore é uma palavra inglesa utilizada originalmente para designar sangue derramado, coagulado. 0 termo gore é encontrado principalmente na crítica norte-americana e suas ramificações. Já o termo splatter (espirrar, esparramar) é preferido pelos ingleses.

${ }^{5}$ Pode-se utilizar glicose de milho ("Karo") tingida com algumas gotas de anilina comestível vermelha, azul e amarela. Misturam-se as anilinas à glicose até obter o tom desejado (por exemplo: um sangue mais escuro, venoso, ou mais claro, arterial). 


\section{Urdimento}

${ }^{6}$ Uma visita ao blog Digital Trash (http:// www.ewpdigitaltrash.blogspot.com) proporciona um interessante panorama deste tipo produção e fruição artística, amparado em discussões conceituais
Embora seja ligado à história e a estética do cinema, o trash também se manifesta em outras modalidades artísticas. A atração pelo mórbido, sombrio, horripilante é encontrado nas pinturas autobiográficas de Frida Kahlo, nas esculturas e instalações macabras de Damien Hirst, nas ilustrações sobrenaturais de Stefan Heilemann, nas esculturas, pinturas e desenhos neogóticos de Kris Kuksi e H. R. Giger. O flerte com o sexo, a sensualidade, em sua relação ambígua com a morte, é visível nos ensaios fotográficos de Jeffery Scott, nas pinturas falsamente pueris de Mark Ryden, nas fotografias nada tranqüilas e frequentemente sanguinárias de Gottfried Helnwein. O horror clássico é tema das fotografias de Joshua Hoffine; o sangue-e-tripas é instrumento de crítica dos desenhos de James Cauty; e o humor (negro) é presença constante nas esculturas, pinturas e instalações kitsch de Nelson Leirner e Jeff Koons.

Finalizando esta breve incursão pelo universo conceitual do trash, vale a pena sublinhar a proliferação do chamado digital trash ${ }^{6}$ : marcado pela veloz apropriação de elementos (do lixo) da cultura de massa, aliada à popularização dos meios de produção digital (equipamentos digitais e softwares) e da internet, possibilita o surgimento de uma ativa comunidade que cria e compartilha sua própria arte no ciberespaço.

\section{O Grand Guignol}

Surgido em Paris, em 1896, o Grand Guignol tornou-se uma das principais fontes do espírito trash no teatro, com desdobramentos e influências que se estendem até hoje. O Théâtre du Grand Guignol era um pequeno edifício dedicado à montagem e apresentação de espetáculos naturalistas. Segundo Hand e Wilson (2000), o teatro foi instalado na capela de um antigo convento situado em uma viela escura de uma região famosa pela prostituição, o que, segundo os autores, contribuiu muito para popularizar e mesmo criar uma atrativa atmosfera de "perigo", obscuridade e até clandestinidade em torno das montagens. O espaço era bastante reduzido, forçando uma grande proximidade entre palco e platéia - essa proximidade, que limitava muitas das possibilidades cenográficas e de movimentação do elenco, obrigou os artistas a criarem técnicas ilusionistas bastante apuradas.

Oscar Méténier - fundador e primeiro diretor - foi secretário do departamento de polícia de Paris, o que, somado à sua experiência de muitos anos como dramaturgo no Théâtre Libre de André Antoine, forjou sua visão de arte e seu estilo teatral. No início de suas atividades, o teatro do Grand Guignol concentrava-se em dois tipos de espetáculos curtos de forte tendência naturalista: a) moeurs populaires (maneiras populares), pequenas cenas sem conflitos dramáticos, retratando detalhadamente as maneiras e os valores das camadas sociais baixas; b) fait divers (fatos diversos), ilustrando cenicamente 


\section{Urdimento}

pequenas notícias retiradas dos jornais, como roubos, raptos, atentados físicos, etc. Numa mesma noite, apresentavam-se várias peças curtas, intercalando uma história de horror e uma comédia (uma farsa) com outra de horror, e assim sucessivamente.

Em 1898, o teatro foi comprado por Max Maurey, que, percebendo o sucesso que os fait divers alcançavam (em especial os que tratavam de situações violentas e assustadoras), direcionou a maior parte dos espetáculos para o horror. O principal dramaturgo deste período foi André de Lorde, conhecido como o "príncipe do terror", autor de clássicos como O sistema do doutor Goudron e professor Plume (1903), e responsável pela fixação de uma das condutas dramatúrgicas básicas do Grand Guignol: "Murder, suicide, and torment seen on the stage are less frightening than the anticipation of that torture, suicide, or muder" (DE LORDE apud DEÁK, 1974, p. 36). Maurey foi o principal responsável pela transformação do Grand Guignol de teatro naturalista para teatro de horror, apostando na publicidade (um exemplo é a contratação de um médico residente no teatro para as pessoas que passassem mal durante as seções - prática retomada pelos produtores do cinema exploitation).

7"Assassinato, suicídio, e tormento vistos no palco são menos assustadores que a antecipação daquela tortura, suicídio ou assassinato" (TA).

Após anos de sucesso, permeado por críticas que acusavam um esgotamento da estética grandguignolesca, o teatro foi novamente vendido, em 1914, para Camille Choisy, que incrementou a utilização de truques em cena, com o intuito de aterrorizar a platéia. Em 1930, Jack Jouvin assumiu a sala de espetáculos, promovendo uma volta ao horror psicológico, ao lado de novelas policiais e musicais. Tais reviravoltas, empreendidas também por proprietários posteriores, contribuíram para o longo processo de declínio que culminou com o fechamento definitivo do teatro em 1962, gerado em parte pelo desinteresse do público por histórias de horror (DEÁK, 1974) e em parte pela superação técnica proporcionada pelo cinema, em especial os filmes da produtora inglesa Hammer (HAND; WILSON, 2000).

Mortes, crimes, insanidades, sexo, adultério, vinganças, hipnoses, torturas, cirurgias e experiências médicas eram os principais temas dos espetáculos apresentados no teatro do Grand Guignol. O Grand Guignol é herdeiro de duas correntes teatrais: o naturalismo e o melodrama. Do naturalismo é evidente a importância dos detalhes realistas, o foco em eventos brutais e o tratamento moral imparcial dos temas; já a importância da atmosfera, as emoções extremadas, e a presença de elementos desconhecidos e misteriosos são marcas do melodrama. Essa dupla filiação manteve os enredos do Grand Guignol afastados tanto de figuras sobrenaturais, como também de enredos não-lineares e soluções dramáticas inverossímeis. 


\section{Urdimento}

8"Em Les Infernales, de André de Lorde, 0 rosto de um dos internos de um hospício é queimado em um fogão por dois de seus camaradas. Um bulbo elétrico vermelho dava a impressão de se tratar de um fogão quente. Pó de lactose era aplicado ao topo do fogão. Uma bobina incandescente produzia fumaça do pó. 0 mesmo princípio era usado para queimar os olhos com um atiçador de lareira. No topo do atiçador havia um pequeno bulbo elétrico vermeIho coberto de tecido e pó de lactose. Para simular sons de ossos se quebrando, um envelope de borracha preenchido com nozes era colocado no cabelo da vítima. Se era necessário quebrar uma garrafa na cabeça de alguém, essa garrafa era feita de açúcar. Para enforcar ou crucificar alguém, um engenhoso sistema de cintos era usado para suportar o corpo" (TA).
Em relação aos valores subjacentes à exposição dos temas, estudiosos do Grand Guignol apresentam uma divergência central: enquanto František Deák (1974) vê o sensacionalismo, o exoticismo e a amoralidade como fatores definidores do horror grandguignolesco, Hand e Wilson (2000) consideram o Grand Guignol um teatro de forte cunho moralista, embora apoiado em uma moral controversa, com firme crença em uma solução divina ou do destino.

O tamanho reduzido do palco (além das exigências da dramaturgia) induzia a escolha de cenários que representavam locações claustrofóbicas, como celas de prisão, salas, quartos, hospícios, salas de operações, laboratórios. A iluminação, tênue, exercia papel preponderante na criação de ambientes obscuros, que tinham uma dupla função: gerar e manter uma atmosfera sombria, de constante suspense; e esconder possíveis imperfeições do cenário e a realização técnica dos variados truques, que, se visíveis, poderiam destruir a ilusão tão necessária ao desenvolvimento do espetáculo (DEÁK, 1974, p. 40). Da mesma forma, a sonoplastia reforçava as ambiências propostas pela cenografia, buscando a verossimilhança: feitos sonoros produzidos ao vivo - nas coxias e atrás da platéia - com materiais diversos, gemidos, gritos.

No entanto, é a constante produção e utilização de truques cênicos uma das maiores marcas do Grand Guignol, principalmente em cenas de violência. Sangue falso (em pequenas ou jorrantes quantidades - numa espécie de teatro gore avant-la-lettre), maquiagens realistas de ferimentos e deformações colocadas rapidamente no rosto dos atores, facas com lâminas cegas ou retráteis, fumaças, suspensões, membros de borracha, jogos com espelhos eram truques quase obrigatórios em uma noite de espetáculos. Os segredos dos truques eram guardados em sigilo absoluto, tornando-se um dos maiores fatores do mistério que rondava e fazia a fama do Grand Guignol.

In Les Infernales by André de Lorde, the face of one of the inmates of a mental hospital is burned on a stove by two of her comrades. A red electric bulb gave the impression of a hot stove. Lactose powder was applied to the top of the stove. A heating coil produced fumes from the powder. The same principle was used to burn out eyes with a poker. At the top of the poker was a little red bulb covered by tissue and lactose powder. To simulate the sounds of cracking bones, a rubber envelope filled with walnut shells was placed in the hair of the victim. If it was necessary to break a bottle on somebody's head, the bottle was made of sugar. To hang or to crucify someone, an ingenious system of belts was used to support the body (DEÁK, 1974, p. 41). 


\section{Urdimento}

Mesmo que, segundo Hand e Wilson (2000), o poder poético horrorizante do Grand Guignol esteja mais na sugestão e na incitação de um estado de expectativa na platéia que na consumação explícita das ações violentas, é a espetacularidade, a teatralidade dos efeitos trash realizados na cena grandguignolesca que mais interessa para a discussão levada a cabo aqui. Um teatro gore, splatter, onde o efeito cênico (falso, artificial), por mais camuflado que se pretenda, é imprescindível para a criação e a consumação do fenômeno artístico.

Uma das preocupações constantes dos artistas, principalmente dos atores do Grand Guignol é justamente a perfeição no manuseio dos artifícios cênicos: um tom exagerado, um truque mal executado, uma maquiagem mal feita, uma interpretação inverossímil podem transformar um sinistro espetáculo de horror em uma grande e jocosa comédia. Os atores são os grandes responsáveis por esse equilíbrio, andando na "corda-bamba" entre o naturalismo e o melodrama, entre o inesperado e o crível, entre o sentimentalismo e a frieza da técnica. O ator do Grand Guignol deve manter a tensão da cena e o naturalismo emocional do seu personagem e, ao mesmo tempo, executar tecnicamente (e, de preferência, de forma imperceptível) truques e malabarismos nem sempre de fácil resolução.

Apesar de ter fechado suas portas em 1962, o Téâthe du Grand Guignol continua influenciando a criação de vários grupos atuais, interessados no resgate e na renovação desse gênero teatral. Em Londres, a

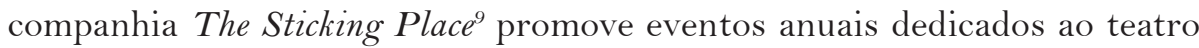
de terror. Nos EUA, o Molotov Theatre Group ${ }^{10}$, fundado em Washington em 2007, e a companhia Thrillpaddlers ${ }^{11}$, de San Francisco, são os principais representantes do ressurgimento do Grand Guignol, procurando manter (com atualizações técnicas) a estrutura narrativa e as coerências formais cristalizadas na primeira metade do século XX. A brasileira Vigor Mortis ${ }^{12}$ afina-se com a tendência conservadora, figurando entre as companhias de referência mundial do novo Grand Guignol. Em New York, porém, os Blood Brothers, da Nosedive Productions ${ }^{13}$, promovem a contaminação dos preceitos grandguignolescos com outras formas narrativas, com acentuado teor erótico, construindo cenas burlescas onde o impacto dos efeitos ganha destaque. Surgida no teatro, a estética do Grand Guignol exilou-se no cinema - com decisivas contribuições à linguagem de horror desenvolvida nos clássicos filmes da produtora Hammer e seus seguidores, entre as décadas de 1960 e 1980 - para então retornar à cena teatral, agora carregada de novas técnicas e referências.

${ }^{9}$ Disponível em: $<$ http://www.thestickingplace.com $>$

${ }^{10}$ Disponível em: $<$ http://www.molotovtheatre.org $>$

${ }^{11}$ Disponível em:<http://www thrillpeddlers.com $>$

${ }^{12}$ Disponível em: $<$ http://www.vigormortis.com.br $>$

${ }^{13}$ Disponível em:

$<$ http://www. nosediveproductions. com> 


\section{Referências bibliográficas}

BAIESTORF, Petter; SOUZA, Cesar. Manifesto canibal: uma declaração de guerra dos que nada tem e tudo fazem contra os que tudo tem e nada fazem. Junho de 2002. Disponível em: <http://www.canibalfilmes.bulhorgia.com.br>. Acesso em: 22 dez. 2008.

DEÁK, František. The Grand Guignol. In: The Drama Review, vol. 18, n. 1. New York: New York University, março de 1974.

HAND, Richard J.; WILSON, Michael. The Grand-Guignol: aspects of theory and practice. In: Theatre Research International. Vol. 25, n. 3. Agosto de 2000. Páginas 266 a 275. Disponível em: <http://www.grandguignol.com/tri_1. htm>. Acesso em: 17 jan. 2009.

HUTCHEON, Linda. Teoria e política da ironia. Belo Horizonte: Ed. UFMG, 2000.

MATTOS, A. C. G. A outra face de Hollywood: filme B. Rio de Janeiro: Rocco, 2003.

MENDONÇA FILHO, Kleber. O que é trash? In: Cinemascópio - Revista de Cinema na Internet. Revista eletrônica disponível em: <http://cf.uol.com.br/ cinemascopio/artigo.cfm?CodArtigo=92>. Acesso em: 16 jan. 2009.

MUECKE, D. C. Ironia e o irônico. São Paulo: Perspectiva, 1995.

PIEDADE, Lúcio de Franciscis dos Reis. A cultura do lixo: horror, sexo e exploração no cinema. Dissertação apresentada ao Curso de Mestrado em Multimeios do Instituto de Artes da UNICAMP. Campinas, 2002. 